\title{
Estrategias electorales frente a la seguridad. Observaciones sobre los posicionamientos de campaña, Buenos Aires (2007)*
}

\author{
Mercedes Calzado** \\ Juan Pedro Gallardo*** \\ Recibido: 2019-02-02 • Enviado a pares: 2019-02-15 \\ Aprobado por pares: 2019-04-29 • Aceptado: 2019-05-20 \\ https://doi.org/10.22395/angr.v18n35a5
}

\begin{abstract}
Resumen
Los tópicos sobre la inseguridad urbana pasaron a ser una parte central de las estrategias electorales locales en los últimos años. El objetivo de este trabajo es analizar las estrategias electorales en disputa a partir de los discursos acerca del crimen urbano en la ciudad de Buenos Aires. El abordaje es cualitativo a partir de la técnica análisis del discurso político. Se analizan los fragmentos referidos a la cuestión de la seguridad urbana al interior de un corpus de material de campaña (gráfico, audiovisual y periodístico) de la elección de jefe de gobierno de Buenos Aires, Argentina, del 2007. Los resultados muestran cómo los espacios políticos mayoritarios incorporaron la seguridad urbana y definieron sus posicionamientos electorales a partir de este tópico. Los discursos de cada espacio político se centran en tres modalidades que diferencian el modo de intervenir sobre la cuestión criminal. Así, se verificó que el discurso del PRO utilizó componentes descriptivos con elementos diagnósticos y propositivos (la ciudad es riesgosa y con las medidas que se tomarán se podrá resolver la situación), el FPV subrayó la clave evasiva del tema securitario para centrarse en la cuestión social, y +BA reforzó el orden prescriptivo (debemos seguir así). Los componentes utilizados por cada candidato configuran un destinatario que define un 'nosotros' diferencial en cada caso: el ciudadano víctima; el ciudadano racional; y un ciudadano protegido.
\end{abstract}

Palabras clave: crimen; política; comunicación política; discursos electorales; gobierno local; criminología; ciudad; ciudadanía; análisis del discurso.

Artículo resultado de investigación derivado del proyecto Comunicación, política y seguridad. Diez años en campaña en la ciudad de Buenos Aires, Universidad de Buenos Aires (Argentina).

* Licenciada en Comunicación, magíster en Investigación Social y doctora en Ciencias Sociales, Universidad de Buenos Aires. Docente de la Carrera de Comunicación de la Universidad de Buenos Aires. Investigadora adjunta del Conicet y del Instituto de Investigaciones Gino Germani de la Facultad de Ciencias Sociales Universidad de Buenos Aires, Argentina. Autora de Inseguro (Editorial Aguilar) y de numerosos artículos publicados en revistas nacionales e internacionales en torno de la problemática de la comunicación, la política y la seguridad pública. Correo electrónico: mcalzado@sociales.uba.ar. Orcid: https://orcid.org/0000-0003-0211-6480

*.. Licenciado en Comunicación Social de la Universidad de Buenos Aires (UBA). Posgrados sobre Actualización en Políticas Públicas y Protección de Derechos y Nuevas Tecnologías y Derechos Humanos (Facultad de DerechoUBA). Colaborador docente de la cátedra Ética y Derechos Humanos de la Facultad de Psicología de la UBA, Argentina. Presidente del Centro de Estudios para la Inclusión Social (CEIS), institución desde la cual desarrolla distintos programas de formación para organizaciones de la sociedad civil, vinculados a la comunicación responsable, la comunicación política y la prevención de los consumos problemáticos. Correo electrónico: gallardojp@hotmail.com. Orcid: https://orcid.org/0000-0003-4334-472X 


\title{
Electoral Security Strategies. Comments on Campaign Positioning, Buenos Aires (2007)
}

\begin{abstract}
The topics of urban insecurity have advanced as a central part of the local electoral strategies in the recent years. The objective of this paper is to analyze the political strategies in dispute based on the problem of urban crime. The approach is qualitatively based on the technique of political discourse analysis. The fragments referring to the issue of urban security are analyzed within a corpus of campaign material (graphic, audiovisual and journalistic) in the election for Head of Government of the city of Buenos Aires, Argentina, in 2007. The results show how most political spaces incorporated urban security and defined their electoral positions based on this topic. The speeches of each political space focus on the modalities that differentiate the way of intervening on the criminal issue. Thus, it was verified that the speech of the PRO used descriptive components with diagnostic and proactive elements (the city is risky and with the measures that will be taken the situation could be resolved), the FPV highlighted the evasive key of the security issue to focus on the social topics, and +BA reinforced the prescriptive component (it should continue like this). The components used by each candidate form a recipient that defines a differential us in each case: the victim citizen; the rational citizen and the protected citizen.
\end{abstract}

Keywords: crime; politics; political communication; elections speech; local government; cities; criminology; citizenship; discourse analysis.

\section{Estratégias eleitorais com respeito à segurança. Observações sobre os posicionamentos de campanha, Buenos Aires (2007)}

\begin{abstract}
Resumo
Os tópicos sobre a insegurança urbana passaram a ser uma parte central das estratégias eleitorais locais nos últimos anos. O objetivo deste trabalho é analisar as estratégias eleitorais em disputa a partir dos discursos sobre o crime urbano na cidade de Buenos Aires. A abordagem é qualitativa a partir da técnica de análise do discurso político. Foram analisados os fragmentos referentes à questão da segurança urbana dentro de um corpus de material de campanha (gráfico, audiovisual e jornalístico) da eleição para Chefe de Governo da cidade de Buenos Aires (Argentina) no ano de 2007. Os resultados mostram como os espaços políticos majoritários incorporaram a segurança urbana e definiram seus posicionamentos eleitorais a partir desse tópico. Os discursos de cada espaço político se centram em três modalidades que diferenciam o modo de intervir sobre a questão criminal. Assim, verificou-se que o discurso do PRO utilizou componentes descritivos com elementos diagnósticos e propositivos (a cidade oferece riscos e com as medidas que serão tomadas poderemos resolver a situação). O FPV destacou a chave evasiva do tema da segurança para se concentrar na questão social e o + BA reforçou a ordem prescritiva (devemos continuar assim). Os componentes utilizados pelos candidatos configuram um destinatário que define um "nós" diferencial em cada caso: o cidadão vítima, o cidadão racional e o cidadão protegido.
\end{abstract}

Palavras-chave: crime; política; comunicação política; discursos eleitorais; governo local; criminologia; cidade; cidadania; análise do discurso. 


\section{Introducción: orden y autonomía en territorio porteño}

La ciudad capital de Argentina se encuentra atravesada desde su etapa moderna por toda una serie de debates en torno a la necesidad de restaurar un orden corrompido por el accionar delictivo y sobre las maneras de optimizar la administración del Estado para lograr la mayor protección de las víctimas (Caimari, 2009; Caimari, Andrade y Shindell, 2016). No obstante, a partir de la reforma de la Constitución Nacional de 1994, se incorporó la gestión local del recurso policial como elemento central del debate.

A partir de la reforma constitucional, la ciudad de Buenos Aires se constituyó como territorio autónomo, eligió por primera vez a su jefe de gobierno (que hasta entonces era definido por el gobierno nacional) y comenzó a tener la posibilidad de delinear su propia política criminal y de conformar su fuerza de policía. Sin embargo, con Fernando de la Rúa como primer jefe de gobierno de la ciudad aparecieron los vaivenes y tensiones con el gobierno nacional para traspasar la Policía Federal, que estaba a cargo de la nación. Fruto de esa disputa y de las discordias acerca de cómo entender la autonomía local, se sancionó la Ley 24.588, conocida como "Ley Cafiero": entre otros puntos, el artículo 7 inhabilitaba a la ciudad a contar con una fuerza policial propia, a la vez que especificaba que la Policía Federal seguiría operando como "garantía de los intereses de la Nación" en la ciudad. Este artículo estuvo vigente hasta agosto del 2007 (Ríos, 2013).

En ese año clave para el debate local sobre la seguridad y las fuerzas policiales se desenvolvió el proceso eleccionario del 2007, año en el cual ganó por primera vez una nueva fuerza política: Propuesta Republicana (PRO), bajo el liderazgo de Mauricio Macri, un referente que se convertiría central en el escenario político argentino —al punto de ganar la elección presidencial en 2015- Su principal contrincante, Daniel Filmus, pertenecía al espacio político a cargo del gobierno nacional, el Frente para la Victoria, liderado por Néstor Kirchner. El tercer referente en la disputa fue Jorge Terlerman, quien era vicejefe hasta que asumió formalmente la jefatura de gobierno el 13 de marzo del 2006, luego de la destitución del entonces jefe de la ciudad, Aníbal Ibarra, por el incendio de un local durante un recital (Cromañón)'.

Los fuertes debates por el control de la policía estuvieron asociados al modo en que se gestionó un elemento que en la década de 1990 había emergido como una novedad en las agendas mediáticas y políticas: el sentimiento de inseguridad (Kessler, 2009). A la par con la profundización de la desigualdad económica, aquella década trajo consigo una ampliación del problema del delito en la calle y, como resultado, un incremento de las tasas de denuncias de hechos delictivos y su visibilización mediática

Esta tragedia ocurrió el 30 de diciembre de 2003 y dejó 194 jóvenes muertos. Sus familiares y la oposición política de la ciudad promovieron el juicio político del mandatario, ya que lo responsabilizaban por el hecho. El proceso fue llevado a cabo por la Legislatura porteña, quién se expidió definitivamente el 7 de marzo del 2006 fallando en contra de su continuidad en el cargo. 
(Martini y Pereyra, 2009). ciudades como Buenos Aires comenzaron a medir el grado de victimización de los ciudadanos a través de encuestas específicamente dirigidas a quienes hubiesen sido víctimas de un delito. Si bien los índices de homicidios y robos para el 2007 se encontraban controlados en la ciudad (SNIC, 2007), el umbral de aceptabilidad de la violencia urbana no se había modificado sustancialmente y se sostuvieron las demandas de intervención estatal (véase Kessler y Merklen, 2013).

La elección del 2007 estuvo encuadrada en estas tensiones y, de algún modo, los debates y opiniones difundidos por las principales fuerzas políticas participantes tienen allí su raíz y fundamento. Estas controversias obedecieron a construcciones preexistentes, por cierto, condicionantes del momento en el cual tuvieron lugar. Recordemos que el criminólogo David Garland considera que, por lo general, los actores políticos operan en un campo estructurado por fuerzas cuyas lógicas no pueden parar. Por tal motivo, "son quienes llevan adelante los últimos movimientos más que quienes llevan adelante los primeros" (Garland, 2012, p. 28) y quienes deben actuar en medio de las tensiones imbricadas en instituciones, valores culturales y conjuntos sociales activos e intensos.

Estos factores estructurantes permiten distinguir en cada uno de los posicionamientos discursivos la disputa de tradiciones políticas opuestas, sea por los intereses que defienden o por las ideas que sostienen. Los principales candidatos de la elección del 2007 fueron la encarnación y la mejor expresión de estas tensiones del campo. Los intereses de los espacios políticos, lejos de ser estancos, se encuentran en permanente circulación, interacción, resignificación y también, por qué no, contradicción. Quienes ingresan al ágora electoral forman parte activa de la coyuntura, escenario que envuelve el desarrollo de las acciones y el despliegue de los discursos proselitistas.

Ya transcurrió más de una década de la elección del 2007, pero su importancia sigue estando presente en la coyuntura, tanto local como nacional. Esta contienda funciona como un laboratorio de análisis sobre la seguridad urbana, el discurso político, la comunicación y las etapas eleccionarias. Por un lado, porque permite revisar el posicionamiento discursivo de Mauricio Macri y su espacio político, triunfadores en 2007. Esta elección consolidó un modelo discursivo y comunicativo de la gestión sobre el espacio local, que permitió al PRO alcanzar la presidencia de la nación en el 2015 con elementos discursivos asociados a la seguridad urbana, similares a los del 2007. Por otro lado, esta contienda funciona como un laboratorio para entender las características de los sentidos de la seguridad y la apelación a la ciudadanía en épocas de campaña.

Los discursos sobre el crimen en momentos electorales tienen su base en los procesos que autores como Garland (2000) asocian a una nueva experiencia sobre el crimen y la inseguridad vinculada con las transformaciones económicas de la 
modernidad tardía. Los cambios en las sensibilidades sociales impactan en este sentido en los modos de entender, debatir y compartir las definiciones sobre el crimen y sus posibles modos de conjura. Uno de los primeros momentos en que la literatura ubica el proceso de generación de campañas en torno del delito ocurrió en Estados Unidos durante la década de 1960 (Gest, 2001), cuando el miedo tiñó parte de las intervenciones electorales, camino que se mantuvo en los sucesivos sufragios. Particularmente, el criminólogo Jonathan Simon (2012) revisó el proceso por el cual las retóricas de la seguridad se plasmaron en las campañas a presidente, alcalde y especialmente a gobernador en los Estados Unidos. Este escenario fue años después, en paralelo al debilitamiento del estado de bienestar, similar en Europa. Aun con estas características electorales del norte occidental, solo hasta la década de 1990 la cuestión del crimen en clave de inseguridad se incorporó como un eje central de debate en algunos países sudamericanos (Dammert y Tobar, 2017) como Argentina, Brasil, Chile y Uruguay. Tal como lo analiza Kessler (2011) para el caso argentino, cuando el sentimiento de inseguridad se profundizó a finales de los años noventa del siglo XX, los relatos sobre la inseguridad y su gestión cotidiana también se modificaron. Nuestra preocupación entonces se vincula con el modo en que las narrativas sobre el crimen se hacen carne en las estrategias discursivas del campo político en épocas electorales.

En los últimos años surgieron investigaciones iniciales sobre las campañas electorales vinculadas con apelaciones a la cuestión de la seguridad en Sudamérica. De allí que este artículo retome trabajos que revisan el delito en contextos de campaña (Calzado, Fernández y Lio, 2013; Calzado, 2015; Colombo, 2011; Dallorso y Seghezzo, 2015; Fleitas, 2014), como un conjunto de investigaciones que analizan la relación entre democracia y punitivismo en términos más amplios (Beckett, 1997; Beckett y Godoy, 2008; Beckett y Herbert, 2010; Chevigny, 2003; Del Olmo, 2000; Hall, Chas, Jefferson, Clarke y Roberts, 2013; Pegoraro, 2001; Sozzo, 2016).

Buscamos revisar el problema del crimen en época electoral desde una perspectiva comunicacional para adentrarnos en la comunicación política en clave cualitativa (Karpf, Kreiss, Nielsen y Powers, 2015), en tanto entramado de sentidos sociales que ingresan en la disputa del espacio público.

Caletti (2001) recalca que

La política que se cumple en el espacio de lo público toma necesariamente los caminos de la comunicación, así como la comunicación que se cumple a la vista de los otros — a la luz pública — es, en último término, inescindible del carácter político de la vida social. (p. 47)

De allí que consideremos que la relación entre comunicación y política ayude a comprender la manera en la cual la cuestión de la seguridad ingresa en las agendas de la comunicación electoral. Entendemos la comunicación política como la confluencia 
entre los discursos mediático, político y de la opinión pública. Entre estos planos existe un proceso dinámico, de enfrentamiento, y final incierto. En términos de la ya clásica formulación de Wolton, la comunicación política implica "la selección de los temas y de los problemas sobre los cuales se ajustan los enfrentamientos cognitivos e ideológicos del momento" (1998, p. 111). En este trabajo nos detenemos en uno de los planos de la tríada definida por este autor: el de los discursos producidos por el campo político. Un discurso que en la actualidad debe ser interpelado en tanto discurso mediatizado, ya que la mediatización de las sociedades industriales "afecta todos los discursos sociales, y el discurso político en particular" (Verón, 1987, p. 11).

Desde la teoría de los discursos sociales de Verón (2004), el discurso político no es un discurso, sino un campo discursivo (Verón, 1987). Por tanto, para revisar los juegos presentes en el discurso debemos recordar que "toda producción de sentido es necesariamente social: no se puede describir ni explicar [...] un proceso significante sin explicar sus condiciones sociales productivas". Y, en sentido inverso, "todo fenómeno social es, en una de sus dimensiones constitutivas, un proceso de producción de sentido, cualquiera que fuere el nivel de análisis (más o menos micro o macro sociológico)" (Verón, 2004, p. 125). Es decir, no se debe realizar el análisis desde un reduccionismo semiótico, ni se debe realizar con base en representaciones que reflejan una realidad exterior.

Desde la teoría de los discursos sociales revisamos las propiedades discursivas invariantes de las intervenciones de campaña en torno a la seguridad, así como las propiedades diferenciales que se producen dentro del juego del discurso. Los discursos tomados como corpus (Boutaud y Verón, 2007) permiten reconstruir las huellas de las operaciones discursivas alrededor del crimen y las promesas de campaña para contenerlo.

Dentro del campo del discurso político se requiere la construcción de un adversario que haga posible una disputa entre enunciadores que se enfrenten como enemigos. "Hablar de 'enunciador' implica una modelización abstracta que permite el 'anclaje' de las operaciones discursivas a través de las cuales se construye, en el discurso, la 'imagen' del que habla" (Verón, 1987, p. 13). En un "acto de enunciación", es decir, de la producción de un enunciado, se definen múltiples actos de enunciación a partir de las réplicas que los distintos enunciadores políticos realizan sobre los enunciados de sus contrincantes. Con el otro positivo al que va dirigido el discurso político, el enunciador posee una "creencia presupuesta", ideas, objetivos y valores similares a los del enunciador (el prodestinatario, en términos de Verón, con quien se forma un "colectivo de identificación" definido por un 'nosotros' inclusivo). En tanto el otro negativo (el contradestinatario) se produce como "inversión de la creencia", los valores e ideas del destinatario se actualizan como inversos respecto de aquellos que posee 
el enunciador. Los destinatarios indefinidos en sus votos y creencias (los paradestinatarios) no tienen una posición en este acto; son los indecisos, sujetos a los que va dirigida la persuasión del discurso político. Como lo sintetiza Verón: "El discurso político es un discurso de refuerzo respecto del prodestinatario, de polémica respecto del contradestinatario, y de persuasión solo en lo que concierne al paradestinatario" (1987, p. 16).

El enunciado que analizamos a lo largo de este artículo se relaciona con los sentidos que giran en torno de un tópico específico: la seguridad urbana. La ampliación del discurso político y mediático sobre la inseguridad en los últimos años en la Argentina indica un contexto particular para su definición. En este sentido, es preciso tener en cuenta los elementos contextuales del discurso político, para lo cual es preciso considerar sus rasgos lingüísticos y extralingüísticos (Mangone y Warley, 1994, p. 28). En el acto de enunciación, los vocablos de la seguridad funcionan como consenso sobre un problema público común, y como la forma de establecer desde allí quién es el 'nosotros' que quiere vivir seguro, el otro que produce inseguridad y los actores que según cada espacio político son capaces de intervenir sobre la problemática². Nuestra búsqueda supone revisar las variaciones y los invariantes en el plano del enunciado, y en estas páginas nos centramos particularmente en el análisis de los componentes: "elementos capaces de definir las modalidades a través de las cuales el enunciador construye su relación con las entidades del imaginario" (Verón, 1987, p. 16).

El objetivo de este trabajo, por lo tanto, es analizar los componentes discursivos de los candidatos porteños del 2007 vinculados al tema de la seguridad. En términos más generales, procuramos aportar elementos útiles para pensar las formas de interpelación de la ciudadanía a través de los problemas del delito urbano en otros contextos electorales locales y nacionales. Para seguir este camino, en las páginas que siguen presentamos primero las definiciones metodológicas tomadas para la realización del trabajo, para luego avanzar en los principales resultados analíticos y, hacia el final, establecer las conclusiones.

\section{Metodología}

Los resultados de este trabajo fueron analizados bajo un paradigma interpretativo y a través de las herramientas que brinda el análisis del discurso político. Seguimos, para ello, el planteamiento de Verón (1987) según el cual el discurso político está formado por cuatro componentes —o modalidades-, desde los cuales el enunciador construye su red de relaciones con las entidades del imaginario: i), el descriptivo, desde

La seguridad se entiende como la construcción cultural e histórica que implica la definición de los márgenes de la violencia tolerable y la no tolerable. Seguimos la noción "sociedades de seguridad" (Foucault, 2000) para las cuales la protección, en tanto imperativo categórico de la gestión política, se convierte en elemento central para el gobierno de las poblaciones. 
el cual el enunciador ejercita la constatación y realiza el balance de una situación en el presente del indicativo; ii), el didáctico, que enuncia un principio general desde el saber sin marcar la subjetividad del enunciador; iii), el prescriptivo, del orden de la necesidad, del deber ser, y iv), el programático, desde el cual define compromisos, su poder de hacer.

La etapa escogida para poner en juego esta herramienta metodológica fue la elección a jefe de gobierno del 2007 en la ciudad de Buenos Aires, por considerarla un momento en el cual se hace posible revisar la presencia de huellas discursivas que permitan comprender los posicionamientos de los candidatos en torno a la temática de la inseguridad. Revisamos las discursividades sobre la seguridad en un corpus de materiales de los principales candidatos en disputa: Mauricio Macri, Daniel Filmus y Jorge Telerman. El relevamiento se realizó durante el mes anterior a la primera vuelta (3 de junio), y los quince días previos al balotaje (24 de junio). Los materiales de análisis se distribuyeron de la siguiente manera:

- Material audiovisual: un debate televisivo entre los tres candidatos principales y dos discursos de campaña.

- Cinco folletos publicitarios.

- Once spots audiovisuales (tres del FPV, tres de +BA y siete del PRO).

- Plataformas digitales: blogs y sitios web de los candidatos.

- Veintiún materiales gráficos: diarios Clarín y Página 12 (del 20 de mayo al 24 de junio de 2007). La información recabada posibilitó reconstruir en clave cualitativa el contexto de la contienda, las maneras en que apareció la cuestión de la seguridad en los discursos y las estrategias de posicionamiento de los candidatos.

Somos conscientes de la limitación de revisar el discurso dentro de diversos soportes (televisivo y gráfico) que contienen características particulares no comparables entre sí. Pese a esta dificultad, en esta instancia de la investigación resolvimos avanzar en la búsqueda de núcleos invariantes en torno de los significados de la seguridad en distintos soportes.

Dentro del material relevado extrajimos los fragmentos en que los candidatos hicieran referencia a la cuestión de la seguridad de manera directa o indirecta. Para dar cuenta del contexto de la elección incluimos las noticias periodísticas con referencias a las intervenciones de los candidatos sobre seguridad. Una vez seleccionado ese corpus específico, identificamos y analizamos en las piezas los fragmentos que contuvieran elementos discursivos en torno al tópico de la seguridad y revisamos allí su tratamiento desde los indicativos discursivos. Para ello, no tuvimos en cuenta la individualidad de los candidatos, sino la forma que adopta la cuestión de la seguridad 
en sus intervenciones. Los resultados muestran la definición de estrategias discursivas diferenciales entre los tres candidatos y posicionamientos particulares de cada uno de estos espacios políticos que presentamos en los resultados que siguen a continuación.

\section{Resultados: claves diferenciales en el abordaje securitario}

¿De qué forma los candidatos en el 2007 abordaron uno de los temas de mayor preocupación y repercusión social? ¿Cómo se diferenciaron de sus contrincantes? En Buenos Aires la elección endilgó a los tres aspirantes a jefe de gobierno la obligación de intervenir, con mayor o menor fuerza, con respecto a sus futuros planes alrededor de la situación criminal.

Los discursos se desenvolvieron a partir de herramientas enunciativas particulares puestas en juego por los espacios en disputa. Antes de sumergirnos en ellas, debemos tener en cuenta que "las subjetividades que se construyen habilitan los procesos identificatorios que dan forma al cuerpo social y los movilizan en torno a objetivos, propuestas o consignas" (Arnoux, 2008, p. 90). Los candidatos son parte de la agenda política, mediática y social, motivo por el cual deben incluir elementos discursivos que retomen una agenda de la seguridad que los excede y a la que ellos mismos contribuyen. Ahora bien, la clave, el patrón rítmico que gobierna el involucramiento de cada candidato frente a la problemática de la seguridad, es diferencial. En este sentido, los resultados de nuestra investigación revelan que en la campaña del 2007 se subrayaron tres modalidades discursivas en las principales intervenciones sobre la seguridad urbana: descriptiva y programática; evasiva, y prescriptiva.

\section{El PRO: de la clave descriptiva a la programática}

La temática de la violencia urbana fue un eje central de la campaña del PRO3. La clave desde la que entonaron las intervenciones sobre la problemática fue particularmente descriptiva, con elementos diagnósticos y propositivos. El diagnóstico se centró en que el exterior, la vía pública, se había convertido en lugar riesgoso: salir a la calle había pasado a ser un peligro cotidiano en una ciudad que había sabido ser segura. Según O'Malley (2006), "los riesgos no son considerados como intrínsecamente reales sino como una modalidad particular en que los problemas son visualizados, imaginados o enfrentados" (p. 36). La campaña se recuerda el espejo del riesgo que devuelve una calle, un barrio, la ciudad. La descripción de los escenarios de peligro inminente implica una manera de recordar la caída de la ciudad con un pasado ideal, la realidad de un peligro inminente y la posibilidad de un futuro que aún se puede modificar.

"Mientras ustedes discutían estas cosas lafirmaba Mauricio Macri durante su intervención en el debate realizado entre los tres principales candidatos en el programa

Para ampliar el análisis sobre la historia y las estrategias de campaña del PRO, ver Vommaro, Morresi y Bellotti (2015). 
político A dos voces de la señal de televisión por cable TN (23/05/2007)] se cometieron diez delitos en la capital". Los números indican el riesgo a ser víctima. Por eso los toma como efecto de cierre de la intervención en el único debate televisivo entre los tres principales candidatos. En el debate, Macri subrayó: "Un hurto cada diez minutos, un robo cada tres, un intento de privación de la libertad cada diez. No se puede seguir hablando, son muchos años que les prometen y no cumplen". El candidato reforzó el imaginario social crítico de la política según el cual decir no es hacer; por lo tanto, el tiempo que estarían perdiendo en verter palabras en una pantalla no condeciría — según el postulante - con las necesidades de los electores. Macri acentuó la idea de que la decisión estaba en manos del votante, motivo por el cual no habría tiempo para seguir debatiendo un diagnóstico que, según su entender, era concensuado entre la ciudadanía y demostrado matemáticamente por las estadísticas. Desde el número procura legitimar sus palabras. Para O'Malley, lo que es específico del riesgo "es que se trata de una técnica estadística y probabilística, a través de la cual grandes cantidades de eventos son clasificados en una distribución que a su vez es utilizada como un medio para hacer predicciones probabilísticas" (2006, p. 31). La puesta en acto del peligro a través de un detalle numérico hace que Macri se legitime por un diagnóstico que no necesariamente tiene que tener una contraparte estadística oficial.

Pero como la intensión discursiva del PRO estaba lejos de mostrarse como un espacio que analiza el entorno, sino que más bien buscaba posicionarse como una alternativa de gestión eficaz y eficiente, el diagnóstico fue acompañado por una segunda clave de intervención discursiva. La clave propositiva le permitió inmediatamente ubicarse en propuestas "concretas" de campaña. De allí su eslogan "estaría bueno". "Estaría bueno salir tranquilo a la calle, que los que roben no puedan salir", aseguraba un hombre frente a una cámara en un spot de este espacio político. En las publicidades, los vecinos de la ciudad en situaciones cotidianas recuerdan sus deseos formulados de tal modo que se transforman en tan simples como posible. En otro spot, un joven prolijamente vestido camina por la calle, y de su boca salen las palabras que podrían ser el reflejo de un pensamiento de cualquier vecino al pasar: "Estaría bueno que aprendiéramos [...]". La escena se corta y la idea individual se encadena con la de otra persona, en este caso un hombre mayor sentado sobre una grada de fútbol con ropa deportiva: "[... que con mayor educación habría menos inseguridad". El futuro parece estar a la vuelta de la esquina si en el sufragio se elige la alternativa de un programa político focalizado en hacer algo sobre un objeto tan práctico como inmaterial: la seguridad urbana.

Como si se tratara del juego infantil en el que una palabra se suma a otra y luego a otra hasta transformarse en una frase con sentido, los vecinos parecen aspirar a tener ideas comunes y ser capaces de transformar una simple noción en una idea de cambio concreta. Así, desde el condicional, se enumera un conjunto de aspiraciones 
que, lejos de ser un horizonte de deseos imposibles o ensoñaciones, devienen condiciones de posibilidad concretas de cambio. Mauricio Macri cierra los spots con una certeza: "Va a estar bueno Buenos Aires". Los verbos en infinitivo, la definición de un futuro cercano, recorren las formulaciones. El momento está llegando. Las ideas colectivas se muestran construyendo un modo de pensar común y un camino que lo materialice. Macri, en uno de los spots de la campaña, mira a la cámara rodeado de verde, en un espacio al aire libre, con sol. "Estamos convencidos que la seguridad, la educación, la salud van a estar buenas en Buenos Aires". Llegó la hora de concretar las aspiraciones. La clave programática acompaña entonces el diagnóstico común. Se puede hacer, se va a hacer: "Va a estar bueno Buenos Aires".

\section{El Frente para la Victoria (FPV) y la clave evasiva}

La clave para intervenir frente al debate vinculado con la problemática de la seguridad urbana por parte del FPV es, de alguna manera, evasiva. Decimos "de alguna manera" porque el tema estaba ubicado en la agenda pública y el candidato no pudo descartarlo de plano; algo debía decir. Esto sucedió especialmente en la segunda vuelta (que enfrentó a Macri y a Filmus), cuando la cuestión securitaria fue tomada por el macrismo como eje de campaña. Aquí, el candidato del FPV incluyó en un tono neutro el ítem seguridad, por ejemplo, en una de sus publicidades gráficas: "gracias por elegir educación, seguridad y soluciones". Filmus se posicionó al arrancar la segunda vuelta tomando algo de la parte discursiva faltante del primer tramo de la elección.

De todos modos, la clave predominante a lo largo de su campaña fue la evasiva: evitar intervenir y debatir sobre seguridad. Para el FPV este elemento discursivo se transformó en un déficit, por cuanto el planteamiento que acentúa estaba centrado en la necesidad de fortalecer las políticas sociales llevadas adelante por el gobierno nacional; evadió la dimensión de las políticas de seguridad, por considerarlo un eje discursivo de "otros" y centrarse en la problematización más general de la cuestión social.

Esta posición quedó plasmada el 19 de mayo del 2007, en un acto realizado en el barrio popular de Villa Lugano, donde Filmus compartió el escenario con el entonces presidente Néstor Kirchner. Allí, según palabras recogidas por el diario Clarín al día siguiente, afirmó: "en las elecciones solo hay dos opciones: volver al hambre y a la marginalidad de la derecha y el neoliberalismo, o avanzar en el sendero de la justicia social. No nos equivoquemos: o volvemos hacia atrás o seguimos con el presidente (Kirchner)". El posicionamiento connotativo del candidato, el sentido privilegiado de sus piezas gráficas, audiovisuales y sus discursos revelan el refuerzo del vínculo con las palabras trabajo y educación.

Esto se visualizó en el debate de Filmus con Macri y Telerman en A dos voces. En un fragmento, la pantalla se divide entre los tres contrincantes y el postulante por 
el FPV parece solo mirar la disputa desde el costado derecho. Gesticula, se muestra molesto y cuando finalmente interviene, cambia la clave: "la pregunta a Macri es ¿por qué las becas estudiantiles, por qué los cursos de capacitación están en una agencia de seguridad?" A lo que el candidato del PRO contesta nuevamente, en clave de efectividad, "porque hay que coordinar", y mantiene la calma. Filmus vuelve a atacar con irritación y tono crítico: "hay una idea de criminalizar la pobreza". Macri mantiene la calma: "ite puedo contestar?", le pregunta. Filmus tira la toalla y deja que su contrincante responda: "¿vos sabés que los que más sufren el delito y el crimen según las estadísticas son los más pobres? Tenemos que cuidarlos. Si a ellos no los protegemos, ellos no pueden pagarse policía adicional, no pueden comprar alarmas, no pueden tener custodios". El candidato del PRO utiliza el territorio de Filmus, retoma desde su clave programática el eje de la seguridad para diagnosticar y comprometerse con "los más pobres" y dificulta la respuesta del candidato del gobierno nacional. "Ellos necesitan políticas de inclusión coordinadas, no puede ser que cada ministerio haya intentado hacer cosas y de mano de la politiquería y los punteros nunca el resultado se concrete. Coordinemos". La evasión del FPV se resuelve con la dificultad de intervenir en la disputa discursiva en torno de la violencia urbana.

\section{+BA y la clave prescriptiva}

El signo de adición representado por el más inicial del logo del partido que impulsaba la reelección de Jorge Telerman como jefe de gobierno revela la clave prescriptiva, el orden del deber "seguir así". Los spots y discursos de campaña reforzaron la idea de una gestión de gobierno que había comenzado pocos meses antes y tenía mucho aún por hacer. El orden de la necesidad de continuidad se acentuó en la imagen de un jefe de gobierno que "tiene en la cabeza" la gestión y puede y debe volcar su experiencia y avances en una nueva etapa de gobierno.

El discurso de continuidad sigue una característica tradicional de todo proceso electoral en el que los candidatos que ocupan un cargo público optan por emitir mensajes positivos antes que negativos al comenzar la campaña. De allí que las imágenes y palabras de Telerman durante el proceso recalcaran lo hecho y por hacer a partir de las intervenciones realizadas por el candidato y gestor. Su campaña, como otras que buscan la continuidad, es mucho más retrospectiva que prospectiva; es decir, priman más los argumentos sobre el pasado, sea para criticarlos o explotarlos afirmativamente. La estrategia de +BA acentuó el pasado cercano desde la revitalización de la figura del candidato.

Las imágenes de campaña se centraron en la calvicie de Jorge Telerman. "Votá al pelado. El único que tiene la ciudad en la cabeza". En una de las publicidades, la 
cabeza del candidato se transforma en una urna, se abre e ingresan con facilidad las que son identificadas como las principales necesidades de los votantes:

Más plazas para los nietos y los abuelos [entran árboles en la urna], más orden para el tránsito [se depositan semáforos], más subtes para la ciudad [ingresan vías y vagones], más luz para los barrios [entran las luminarias], más cultura para los vecinos [dos bailarines de tango, un proyector de cine, máscaras], más salud para todos [ambulancias], más educación [un pizarrón].

La actitud aditiva no se calma hasta que llega al punto central de la campaña, que cierra — como un final esperado por todos - la cadena de políticas públicas locales: "Más seguridad", recalca la voz en off mientras en la imagen se observa cómo ingresan cuatro patrulleros en fila a la cabeza-urna. El spot finaliza: "Más autonomía. Más Telerman, más Buenos Aires". Políticas públicas plurales, seguridad y autonomía, querer más es continuar con el rumbo, querer más es que la ciudad crezca y para ello, según la matriz que se genera, es preciso avanzar sobre la autonomía a partir del manejo del brazo armado del Estado local, una policía propia.

En una entrevista con el diario Clarín, el entonces ministro de gobierno porteño, Diego Gorgal, fortalecía este planteo con cifras que revelaban un aumento vertiginoso de la seguridad privada (guardias privados que superan en número a los agentes de la Policía Federal Argentina - PFA). En opinión del funcionario, esta situación indicaba que la contratación de vigiladores privados se incrementó de manera proporcional a los delitos. Además, era la prueba de la real preocupación de los porteños, con el agregado de la desigualdad social, debido a que este recurso se concentraba en los barrios más ricos de la zona norte de la ciudad. En tal sentido, sostenía Gorgal:

"El mapa muestra por qué el delito afecta más a los que menos ingresos tienen: son los que dependen del servicio público. Es similar a lo que pasa con la salud y la educación: el de mayores recursos tiene prepaga y un colegio privado, el otro no. La desigual distribución de los guardias también deja en evidencia que la seguridad privada mueve el delito desde las zonas controladas a las que no lo están, aunque no lo hace desaparecer".

Y sentenciaba: "El edificio que tiene un vigilador en la puerta tiene menos posibilidades de sufrir un robo que su vecino que no lo tiene. Pero desde lo general, el delito sólo se corre, la situación general no cambia" (Clarín, 2007).

De esta forma, la autonomía porteña requería, en términos de deber, la continuidad y el avance en materia de seguridad. El diagnóstico se presentó como un escenario común, compartido por los ciudadanos interpelados. Desde su blog, el candidato analizaba así la situación:

Porque muchos tenemos hijos a los que seguimos por celular cuando están en la calle, o porque miramos con cuatro ojos al caminar por un espacio 
mal iluminado, o sencillamente porque la paranoia de los noticieros se nos contagia, todos vivimos preocupados por la inseguridad.

El candidato parecía haber realizado un diagnóstico en sus meses de gestión respecto de un temor tangible en las cifras y en el imaginario porteño, de allí que certificara y prescribiera cómo continuar. La necesidad imperante se transformó en el requerimiento de la creación de una policía propia y el llamado a una consulta popular para ratificar el mandato constitucional de creación de una policía local.

Así y todo, la clave prescriptiva esconde un riesgo que se evidencia en el debate entre los candidatos en A dos voces. Allí, Telerman insiste en mirar a la cámara; su interlocutor es el espectador, no sus contrincantes. Demuestra, a diferencia de sus oponentes, el manejo de ciertas técnicas vinculadas al mundo de los medios y la comunicación. Ambiciona — a partir del establecimiento del eje los ojos en los ojos - (Verón, 1983) acercarse al votante, una operación característica del género periodístico en televisión y del relato no ficcional: ganar influencia directa sobre el público al desplazar la figura del presentador/mediador.

Pero el efecto de mirar al espectador durante el debate puede no ser el deseado. El candidato parece no estar dialogando en su contexto inmediato con sus pares candidatos; más bien se percibe que interpela directamente al espectador "haciendo campaña", situación que genera alejamiento en lugar de cercanía con el televidente. "Lo que acaba de decir tomándolo por el lado tremendo de la violación, es tan peligroso desde el costado de la protección de los derechos humanos. Va en contra de cualquier país con economía y estructuras liberales", afirmaba Telerman mirando fijo a los ojos del espectador y no a los de los candidatos. "Este muchacho ve mucho 24 horas", se mofa de uno de ellos. "Usted se confunde la ficción con la realidad", asegura Telerman en respuesta a la propuesta de Macri de crear un registro de ADN de violadores durante el debate. El peligro es que en la identificación de la centralidad del candidato y la definición del deber ser, la clave prescriptiva se oriente hacia el destinatario y el ropaje del candidato que busca votos quede revelada. La ficción del par se desdibuja. De este modo, el candidato abandona su lugar de ciudadano preocupado y ocupado por la ciudad para transformarse en un sujeto en busca de votos, en "un político más".

El acto de enunciación de cada candidato, la producción de sus enunciados, implica la definición del 'nosotros' a partir de la respuesta y la disputa con sus contrincantes. Desde allí apelan al otro positivo, el prodestinatario, a quienes tienen creencias similares a cada candidato con respecto a la política, la ciudad y la violencia urbana. Mediante los componentes que utilizan también se apela a quienes no han tomado una posición y buscan persuadir: los paradestinatarios. La suma del prodestinatario y el paradestinatario imaginables configura un 'nosotros' ideal que diferencia tres modos de configurar a la ciudadanía: el ciudadano víctima; el ciudadano racional, 
y un ciudadano protegido. El discurso del PRO se dirige idealmente a un ciudadano preocupado, un vecino que desconfía de un entorno peligroso y que percibe que se puede convertir en víctima de la delincuencia, motivo por el cual consideraría que el espacio político debe dar respuestas eficaces y veloces a la inseguridad. Por su parte, el discurso del FPV apela a un ciudadano racional capaz de comprender el problema de la seguridad en tanto entidad compleja; por lo tanto, evade tratar de frente la propuesta de políticas criminales y ocuparse de definiciones acerca de la cuestión social. Por último, el frente +BA configura un destinatario conservador, un ciudadano protegido, que se siente más amparado que en el pasado, pero que busca estar más protegido por el gobierno local en el futuro.

La nueva experiencia sobre el crimen que la ciudadanía de la ciudad de Buenos Aires adquirió una década antes de esta elección, así como los cambios políticos relacionados con la autonomía de la ciudad, generaron que los discursos de la campaña del 2007 produjeran intervenciones con significados capaces de apelar a los diversos sentidos sobre el crimen, el Estado y la definición misma de lo que implica ser ciudadano en escenarios de peligro.

\section{Conclusiones}

La reforma de la Constitución Nacional de Argentina de 1994 y el estatus autónomo que adquirió la ciudad de Buenos Aires a partir de entonces establecieron una importante plataforma, desde la cual se erigieron los discursos referidos al delito y la seguridad de cada una de las principales fuerzas políticas locales. La autonomía de la ciudad fue un acontecimiento en la vida de los porteños que permitió el debate sobre la creación de un recurso policial propio que terminó, años después de la contienda electoral del 2007, con su efectiva creación. Por lo tanto, este artículo procuró aportar herramientas para entender la forma en que los candidatos de la elección porteña del 2007 se posicionaron frente al tópico de la seguridad.

Los resultados presentados revelan que, en términos generales, las propuestas en materia de seguridad esgrimidas en la campaña electoral del 2007 combinaron, al igual que en otras ciudades y países, posturas vinculadas al welfarismo penal, como la necesaria reducción de la pobreza y la marginación para la disminución del delito, con las sanciones punitivas, expresadas en el registro de violadores de Macri, o de gestión participativa, como la propuesta de consulta popular para la creación de una policía local de Telerman. Por el contrario, estuvieron ausentes las opiniones favorables a la reformulación de los programas de readaptación de los delincuentes, eje central del paradigma correccionalista. Entre otras cosas, ello corroboró la tesis afirmada por Garland (2012) de que nos encontramos en la actualidad ante un declive del ideal rehabilitador, producto de la crisis del Estado de bienestar que inició en la década de 1970. 
El temor al delito y la sensación de inseguridad acompañan también este proceso de transformaciones, lo hacen como aspecto cultural y del sistema de medios de comunicación masivo. Para dramatizar el delito en clave electoral es necesaria la apelación a una ciudadanía temerosa que reclama protección y castigo. Frente a esta situación, las principales fuerzas políticas de la contienda desplegaron distintas estrategias discursivas para interpelar a sus votantes a la hora de abordar la cuestión de la seguridad.

Esta investigación está centrada en solo una elección; de allí sus limitaciones, que requieren ampliarla a otras campañas locales y nacionales que privilegien el tópico de la seguridad. Pese a ello, los resultados de este trabajo presentan algunas características metodológicas y conceptuales que se pueden revisar para considerar sus regularidades o rupturas en futuras investigaciones.

En primer lugar, los resultados indican cómo el PRO se movió en un eje que fue desde lo meramente descriptivo a lo pragmático y en tal sentido, se posicionó en la forma y los espacios donde los hechos delictivos irrumpen en la vida cotidiana, como el barrio o un comercio. Dentro de este esquema, la atención no estuvo puesta en el sujeto delincuente ni en la gravedad del delito, sino en la ilegalidad en sí misma y en su carácter inminente, en el cual cualquiera en cualquier momento se puede convertir en víctima. Así, Macri diagnosticó que en la ciudad los vecinos vivían bajo una amenaza permanente, como consecuencia de la ineficiente gestión gubernamental. Respaldó su discurso en estadísticas, para luego pasar a la fase propositiva, en la que se privilegiaron las propuestas concretas y se garantizó la reversión de la inseguridad.

El FPV adoptó una estrategia evasiva al intervenir en la problemática de la seguridad urbana. Debió intervenir en el debate porque era una cuestión que se encontraba en el centro de la agenda de discusión política y, a la vez, porque la seguridad estaba bajo su responsabilidad por el manejo del gobierno nacional de la Policía Federal en territorio porteño. Esta situación produjo que no pudiera dejar de manifestarse sobre el tópico, pero que a la vez evitara hacerlo con contundencia. Así las cosas, la clave securitaria apareció de forma solapada en una oferta entremezclada con políticas relacionadas a la inclusión social. Es más, esta fuerza sostuvo que el estado de inseguridad se revertiría a partir de la implementación de este tipo de políticas. Esta afirmación tiene tanto de positiva como de negativa, porque rehuyó del debate sobre políticas de seguridad, situación que reforzó su carácter evasivo.

Finalmente, el frente +BA asumió un rol prescriptivo en la campaña, cuyo principio obedeció a que era la fuerza a cargo del poder ejecutivo porteño que buscaba su revalidación en las urnas. Como resultado, sus mensajes fueron fundamentalmente 
positivos e intentaron transmitir la idea de que se debía seguir en el camino trazado para ir resolviendo las cuestiones pendientes, entre ellas, las vinculadas a la seguridad. El destinatario ideal generado por su discurso fue un ciudadano protegido por la gestión que buscaba seguir mejorando su protección frente a la delincuencia urbana. Por tal motivo, ante la necesidad de resguardo de la población se impulsó, a través de la propuesta de una consulta popular, la creación de una policía local. Al mismo tiempo, se trasladaron los aspectos negativos al FPV, alianza política que gobernaba a nivel nacional y que detentaba la conducción de la Policía Federal. De esta manera, convirtió una carencia de origen en una propuesta de cara al futuro, lo que proyectó continuidad. Su estrategia modela un destinatario conservador que requiere la ampliación de la protección estatal en términos de seguridad.

La contienda electoral de referencia tuvo en Mauricio Macri, Daniel Filmus y Jorge Telerman -los postulantes más votados- una escasa diferenciación propositiva. El primero de ellos, quizás, contó con un marketing más eficaz y coherente. Las pujanzas entre Filmus y Telerman durante la primera parte de la campaña, para ver quién ingresaba al balotaje, solo benefició a Macri. Asimismo, el FPV arrancó la competencia en desventaja porque necesitó ampliar el conocimiento de su candidato en el electorado porteño ("Si lo conocés, lo elegís"), situación que luego intentó remontar a partir de su apego al gobierno nacional ("Nada es imposible si tenés convicciones"). Por el contrario, el PRO focalizó su impronta en la cotidianeidad local y en la propuesta de aumentar la calidad de vida de sus habitantes. En este sentido, apeló fuertemente a un discurso emotivo y no confrontativo.

Como resultado general de esta estrategia enunciativa, el sujeto interpelado por el líder del PRO fue el ciudadano víctima. Ello se sostuvo como consecuencia de un discurso circunscripto a vecinos que son víctimas de la ineficacia del Estado en situaciones relacionadas con la educación o la limpieza, y en el peligro que circunda por la inseguridad. En cambio, Filmus se dirigió al ciudadano racional que eligiera "cambiar la ciudad de la misma forma que se cambió el país". Tampoco tuvo éxito la estrategia del FPV de denunciar el anclaje de Macri en el pasado privatizador del espacio público de la década de 1990.

En cambio, el éxito sí quedó impreso en la estrategia visible en el eslogan del PRO "va a estar bueno Buenos Aires". La proyección hacia el futuro no indica nada del presente ni del pasado: constituye un significante flotante que adquiere su significado en complicidad con el destinatario y en lo que este especule sobre el candidato que la incorpora en su discurso. El deseo de que la inseguridad deje de ser un riesgo del cual preocuparse en la ciudad hizo parte de esa complicidad buscada con un ciudadano entendido como víctima de un peligro posible, y una parte de la abstracción que explica el sentido de un discurso exitoso en la campaña del 2007, que siguió siéndolo 
hasta abarcar un nivel nacional en Argentina en el 2015, con la elección presidencial de Mauricio Macri.

\section{Referencias}

Arnoux, E. (2008). El discurso latinoamericanista de Hugo Chávez. Biblos.

Beckett, K. (1997). Making crime pay. Oxford University Press.

Beckett, K. y Godoy, S. A. (2008). Power, politics, and penalty: Punitiveness as backlash in American democracies. Studies in Law, Politics, and Society. 45, 139-173. https://doi.org/10.1016/S1059 4337(08)45004-4

Beckett, K. y Herbert S. (2010). Banished: The new social control in urban America. Oxford University Press. https://doi.org/10.1093/acprof:oso/9780195395174.001.0001

Boutaud, J, y Verón, E. (2007). Sémiotique ouverte. Itinéraires sémiotiques en communication. Hermès Science.

Caimari, L. (2009). Buenos Aires en la era del "pistolerismo". Modernidades delictivas. Desarrollo Económico, 49(195), 389-419.

Caimari, L., Andrade, L. U., y Shindell, R. (2016). While the city sleeps: A history of pistoleros, policemen, and the crime beat in Buenos Aires before Perón. University of California Press.

Caletti, S. (2001). Siete tesis sobre comunicación y política. Diálogos de la Comunicación, 63, 37-49.

Calzado, M. (2015). Inseguros. Aguilar.

Calzado, M., Fernández, M., y Lio, V. (2013). ciudad segura. Vecindad, víctimas y gubernamentalidad. Confluenze: Rivista di Studi Iberoamericani, 5, 249-263. https://doi.org/10.6092/issn.2036-0967/3768

Chevigny, P. (2003). The populism of fear. Politics of Crime in the Americas. Punishment and Society, 5(1), 77-96.

Colombo, R., (2011). Populismo punitivo y politización de la (in)seguridad urbana en Argentina. En M. Gutiérrez (ed.), Populismo punitivo y justicia expresiva (pp. 183-220). Fabian di Placido.

Dallorso, N., y Seghezzo, G. (2015). Inseguridad y política: el miedo como operador estratégico en las campañas electorales en Argentina. Comunicación y Sociedad, 24, 47-70.

Dammert, L., y Tobar, F. S. (2017). Fear and insecurity in Latin America. En M. Lee y G. Mythen (Eds.), The Routledge International Handbook on Fear of Crime (pp. 339-353). Routledge. https:// doi.org/10.4324/9781315651781

Del Olmo, R. (2000). Ciudades duras y violencia urbana. Nueva Sociedad, (167), 74-86.

Fleitas, M.S. (2014). Democracia, ciudadanía y cuestión social Jujuy-Argentina en la década de 1920. [Tesis doctoral]. Universidad Pablo de Olavide.

Foucault, M. (2000). Defender la sociedad, Curso en el Collège de France 1975-1976. Fondo de Cultura Económica.

Garland, D. (2000). The culture of high crime societies: Some preconditions of recent 'law and order' policies. British Journal of Criminology, 40(3), 347-375. https://doi.org/10.1093/bjc/40.3.347 
Garland, D. (2012). La cultura del control. Gedisa.

Gest, T. (2001). Crime and Politics. Oxford University Press.

Hall S., Chas, C. Jefferson, T., Clarke J. y Roberts, B. (2013). Policing the Crisis. Mugging the State and Law and Order (1979). Palgrave Macmillan.

Karpf, D., Kreiss, D., Nielsen, R., y Powers, M. (2015). Qualitative Methods in Political Communication Research, International Journal of Communication, 9, 1888-1906.

Kessler, G. (2009). El sentimiento de inseguridad. Siglo XXI.

Kessler, G. (2011). La extensión del sentimiento de inseguridad en América Latina: Relatos, acciones y políticas en el caso argentino. Revista De Sociologia e Politica, 19(40), 83-100. https:// doi.org/10.1590/S0104-44782011000300007

Kessler, G. y Merklen, D. (2013). Una introducción cruzando el Atlántico. En R. Castel, G. Kessler, D. Merklen y M. Murard, Individuación, precariedad, inseguridad (pp. 9-31). Paidós.

Mangone, C., y Warley, J. (1994). El discurso político: del foro a la televisión. Biblos.

Martini, S. y Pereyra, M. (2009). La irrupción del delito en la vida cotidiana. Relatos de la comunicación política. Biblos.

O’Malley, P. (2006). Riesgo, neoliberalismo y justicia penal. Ad Hoc.

Pegoraro, J. (2001). Las políticas de seguridad en centros urbanos de Europa y América Latina. Antigua Universidad de Oñati.

Ríos, A. (2013). La Policía Metropolitana de la ciudad de Buenos Aires, gobierno y represión. Derecho Penal y Criminología, 6, 213-226.

Simon, J. (2012). Gobernar a través del delito. Gedisa.

Sistema Nacional de Información Criminal (snic) (2007). Sistema Nacional de Información Criminal. Informe Total País 2007. Ministerio de Justicia y Derechos Humanos de la Nación.

Sozzo, M. (2016). Democratization, politics, and punishment in Argentina. Punishment y Society, 38(3), 301-324. https://doi.org/10.1177/1462474516645689

Verón, E. (1983). Il est là, je le vois, il me parle. Communications 38, 98-120.

Verón, E. (1987). La palabra adversativa. En AA.W. El discurso político. Lenguajes y acontecimientos (pp. 11-26). Hachette.

Verón, E. (2004). La semiosis social. Gedisa.

Vommaro, G., Morresi, S., y Bellotti, A. (2015). Mundo PRO. Planeta.

Wolton, D. (1998). La comunicación política: construcción de un modelo. En G, Gauthier, A. Gosselin y J. Mouchon (Eds.), Comunicación y política. Gedisa. 